\title{
On Determination of Pollution in Urban Junction, Caused by Vehicles
}

\author{
Prof. As. Dr. Asllan Hajderi ${ }^{1}$, Dr. Ing. Shkelqim Gjevori ${ }^{2}$
}

\begin{abstract}
In this study, given the determination of the pollution quantity from vehicles in an urban junction in order to reduce the pollution level and fuel. The pollution caused by vehicles, it is taken based on production years within the EC directives. Types of vehicles circulating are determined based on vehicles state, divided by production years and the type of engine.

For urban junction with roundabout "Zogu Zi", they are performed measurements of vehicles number, that move in an hour, describing way with slowly and relevant time. For this junction it is calculated vehicle speed at the junction and pollution quantity is converted to $\mathrm{g} / \mathrm{min}$ and then it is determined the pollution quantity per hour for existing state of vehicles divided into 5 groups, according to pollution level. For practical application, only vehicles manufactured after 2000 in circulation, it results that can be achieved a pollution reduction at the junction up to 3 times. To realize this, it is proposed the removal of customs duty for vehicles manufactured after 2001 and establishment of additional environmental tax, proportional to the pollution degree for vehicles in circulation.
\end{abstract}

Keywords: vehicle, urban junction, pollution reduction

\section{Introduction}

Nowadays the vehicles number, circulating in urban areas has increased more. During the process of fuel combustion in vehicle engines, gas emissions in vehicle exhaust system contain harmful elements like, carbon monoxide CO, nitrogen oxides NOx, unburned hydrocarbons $\mathrm{HC}$ and soot particles PM, usually 2.5-10 micron size, which have toxic effects on the human body.

The task of reducing environmental pollution has forced the leaders of EU to orient the research towards the vehicles production with fuel consumption and

\footnotetext{
1 "Aleksander Moisiu” University., Professional Studies Faculty, Durres, Albania.

${ }^{2}$ Ministry of Public Works and Transport; Institute of Transport, Tirana, Albania.
} 
pollution degree much smaller. For this purpose, CE has issued directives, which requires from vehicle manufactures, to reduce the pollution level of vehicles in atmosphere and to strengthen technical control in terms of regular maintenance. So, now the challenge is to replace an existing automobile with more efficient and less polluting versions, which constitutes the focus for vehicle manufacturers at the present time.

Table 1.

\begin{tabular}{|c|c|c|c|c|}
\hline Standard & Year of production & $\mathrm{CO} \mathrm{g} / \mathrm{km}$ & $\begin{array}{c}\text { NOx }+\mathrm{HO} \\
\mathrm{g} / \mathrm{km}\end{array}$ & $\begin{array}{c}\text { Particles PM } \\
\mathrm{g} / \mathrm{km}\end{array}$ \\
\hline Euro 1 (S I) & July 1992 - January 1993 & $3.16(2.72)$ & $1.13(0.97)$ & $0.18(0.14)$ \\
\hline Euro 2,3 (S II) & July 1996 - January 1997 & 1.00 & $0.90(0.7)$ & $0.1(0.08)$ \\
\hline Euro 4 (S III) & January 2000 & 0.64 & 0.56 & 0.05 \\
\hline Euro 5 (S IV) & January 2005 & 0.50 & 0.30 & 0.03 \\
\hline Euro 6 (S V) & September 2009 & 0.50 & 0.23 & 0.01 \\
\hline
\end{tabular}

Thus, they are given maximum values of pollutants $\mathrm{CO},(\mathrm{HC}+\mathrm{NOx}), \mathrm{PM}$, that are available for vehicles in circulation, that must respect the manufacturing factories depending on standards Euro1, Euro 2, Euro 3, Euro 4, Euro 5. For passenger automobiles (cars) these values are given in table 1 for diesel vehicles and in table 2 for gasoline vehicles ${ }^{1}$.

Table 2

\begin{tabular}{|c|c|c|c|}
\hline Standard & Year of production & $\begin{array}{c}\text { CO } \\
(\mathrm{g} / \mathrm{km})\end{array}$ & $\begin{array}{c}\text { NOx }+\mathrm{HC} \\
(\mathrm{g} / \mathrm{km})\end{array}$ \\
\hline Euro 1 (S I) & July 1992 & $3.16(2.72)$ & $1.13(0.97)$ \\
\hline Euro 2 (S II) & January 1996 & 2.2 & 0.5 \\
\hline Euro 3 (S III) & January 2000 & 2.3 & 0.35 \\
\hline Euro 4 (S IV) & January 2005 & 1.0 & 0.18 \\
\hline Euro 5 (S V) & September 2009 & 1.0 & 0.16 \\
\hline
\end{tabular}

From tables it is clearly a pronounced reduction of pollution level for produced vehicles after 2000. So for diesel vehicles produced after 2000, compared with those produced before 1996 (Table 1) the pollution reduction results: for carbon monoxide CO 4.5 times, nitrogen oxides and unburned hydrocarbons ( $\mathrm{HC}+$ NOx) 2 times and particulate matter PM, 3 times. In total the pollution reduction for produced vehicles after 2000, compared with those produced before 1996, is about 3 times. As for produced vehicles after 2005, compared with those produced before 2005, the reduction of pollution level is small.

For gasoline vehicles manufactured after 2000, compared with those produced before 1996 (Table 2) the pollution reduction is: for carbon monoxide (CO) 1.5

${ }^{1}$ Hillier V.A.W. \& Peter Coombes (2005) "Hillier's Fundamentals of Motor Vehicle Technology" $5^{\text {th }}$ edition Book 1. 
times and for nitrogen oxides and hydrocarbons $(\mathrm{HC}+\mathrm{NOx})$ up 2.5 times. In total, the reduction of pollution level for vehicles manufactured after 2000, compared with those produced before 1996, is about 2 times. As for vehicles produced after 2005, compared with those produced before 2000, the pollution reduction results: for carbon monoxide (CO) 2.3 times and for nitrogen oxides and hydrocarbons $(\mathrm{NOx}+\mathrm{HC}) 2$ times. In total, the pollution reduction for produced vehicles after 2005, compared with those produced before 2005, is about 2 times.

In these circumstances it is clear that, if in circulation we will have only vehicles manufactured after 2000, the pollution level will be reduced significantly. In this context, this study was undertaken to determine the pollution degree to an urban junction with roundabout, for the current structure of vehicles in circulation in order to know him and consequently the effects on human health. Meanwhile, in order to reduce the pollution, it is proposed the structure with vehicles manufactured after 2000, since the most of the vehicles in our country are with diesel and the change of pollution compared to those produced after 2005 is small. The pollution reduction in urban areas will contribute to the reduction of cancer diseases and consequently in prolonging of human life.

\section{Vehicles number and movement speed in junction}

Determination of pollution from vehicles will be done for "Zogu Zi" junction, located at the entrance of the capital. It is with roundabout and consists from 4 branches, in which 3 branches are 2 lanes per sense, while the branch of main entrance is with 3 lanes per sense (fig. 1 ).

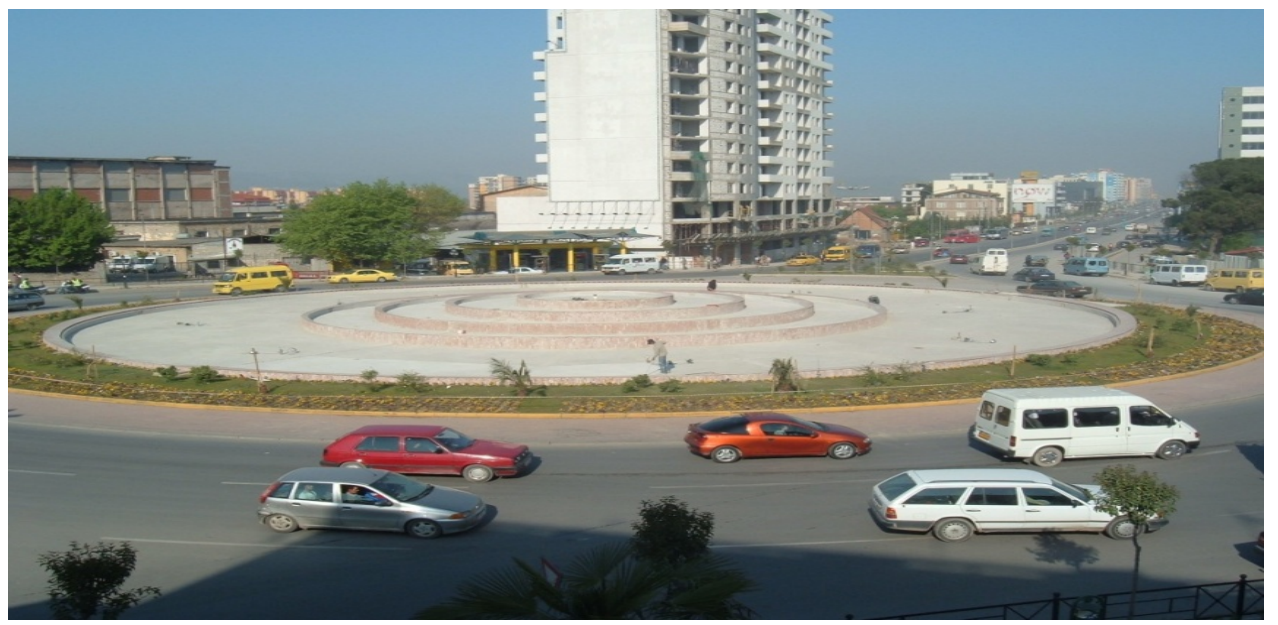

Figure 1. The junction "Zogu Zi" 
The vehicles number in circulation is determined by the survey method. Observer at junction counts vehicles entering into any branch of the junction during one min. Tests repeated three times within an hour and we obtain average values $\mathrm{N}_{1}, \mathrm{~N}_{2}, \mathrm{~N}_{3}, \mathrm{~N}_{4}$ for four branches. The average number of vehicles in an hour $\mathrm{N}$ will be calculated:

$$
\mathrm{N}=60\left(\mathrm{~N}_{1}+\mathrm{N}_{2}+\mathrm{N}_{3}+\mathrm{N}_{4}\right) \text { vehicles/hour }
$$

Measurements are carried out for an week (five working days) and it is taken average number of vehicles for every hour $\mathrm{N}_{\mathrm{h}}$. Then, the average number of vehicles per hour is determined for a given junction (vehicles number at 8 o'clock includes practically average number for $30 \mathrm{~min}$ before and $30 \mathrm{~min}$ after ).

From measurements carried out in February 2013, during an week at different times of the day $\left(7^{00}-21^{00}\right)$. Average number of vehicles circulating in junction $\mathrm{N}_{\mathrm{h}}$, for different hours of the day, is shown in fig. 2 .

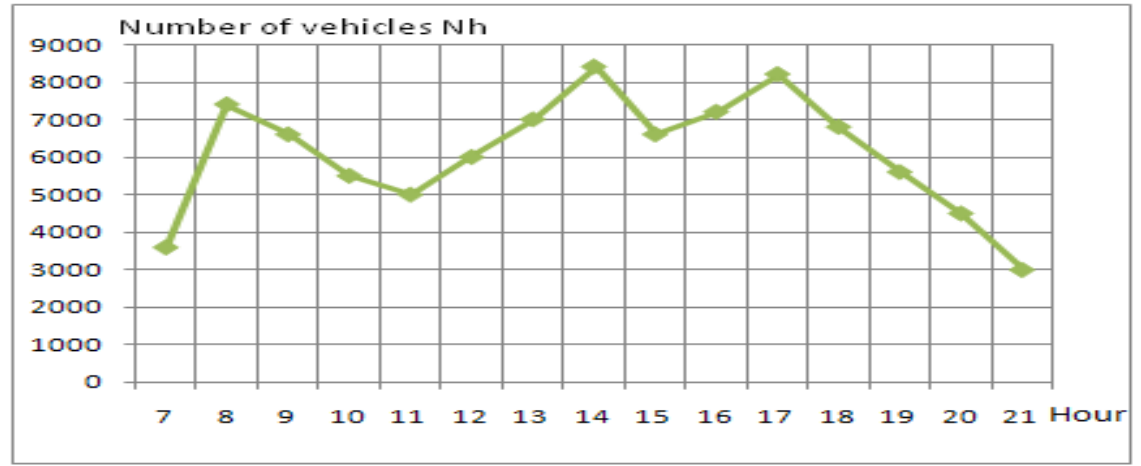

Figure 2 Average number of vehicles per hour in junction, $N_{b}$

The average number of vehicles circulating in this junction is $6090 \mathrm{v} / \mathrm{h}$, while the peak traffic hours (at 8, 14, 17), it increased up to 8400 vehicles/hour, indicating for an exacerbation of traffic in these hours and the reduction of movement speed .

The movement speed at the junction is determined by the survey method. Observer at junction determine the start places of slow vehicles movement, in every entering branch in the junction and he performs the time measurement, that vehicles do from the entrance to the exit of the junction. Then, he measures the described distance for each incoming branch of this junction. Tests are repeated three times within an hour and it is calculated the average value of distance and time, for each branch in different hours of the day. Then, it is calculated the average distance and time for all branches, for each hour. Finally, 
it is calculated the average distance and time for total day, from which we determine the average speed of movement.

From measurements made in February 2013 at the "Zogu Zi" junction, during a week at different times of the day $\left(7^{00}-21^{00}\right)$, we have calculated the average distance, and the corresponding average time for all branches, for different hours of the day, which are given in fig. 3.

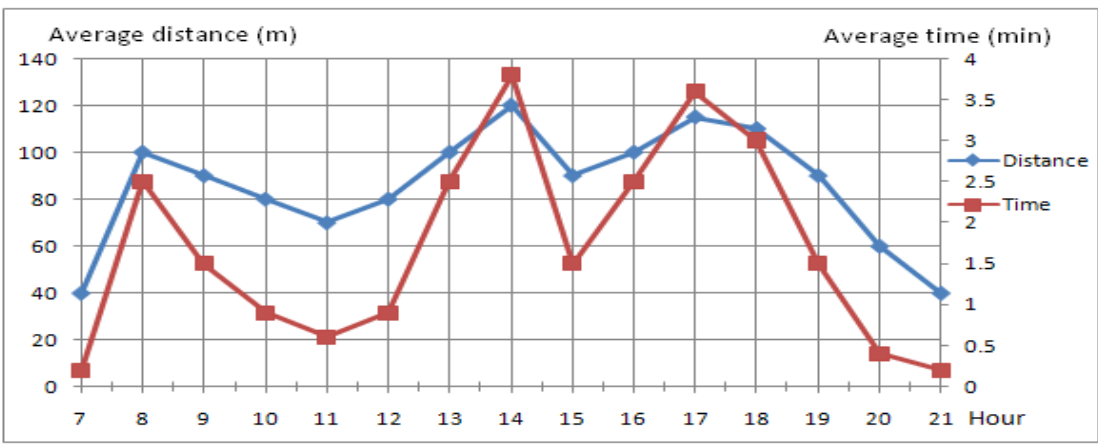

Figure 3. Average distance and time of vehicles at the junction

For this junction it results, that average distance with slow speed is about $85 \mathrm{~m}$, while the average time is $1.7 \mathrm{~min}$, from which we determine the speed 0.05 $\mathrm{km} / \mathrm{min}$. For peak traffic time this distance increases to $120 \mathrm{~m}$, relevant time is $3.8 \mathrm{~min}$, from which the speed decreases up to $0.03 \mathrm{~km} / \mathrm{min}$. While, in the free traffic the distance is $40 \mathrm{~m}$, the time is $0.2 \mathrm{~min}$ and the speed $0.2 \mathrm{~km} / \mathrm{min}$.

The given junction is in the capital and vehicles in circulation are from entire country, therefore the vehicle structure in this junction, will be the same as the total structure, which according to the groups of production year is given in figure $4^{2}$. Diesel vehicles make up $79 \%$ of the total vehicles number in circulation, which has reached in the end 2012 in $487640^{3}$.

Figure 4. The vebicle number in Albania, according to production year

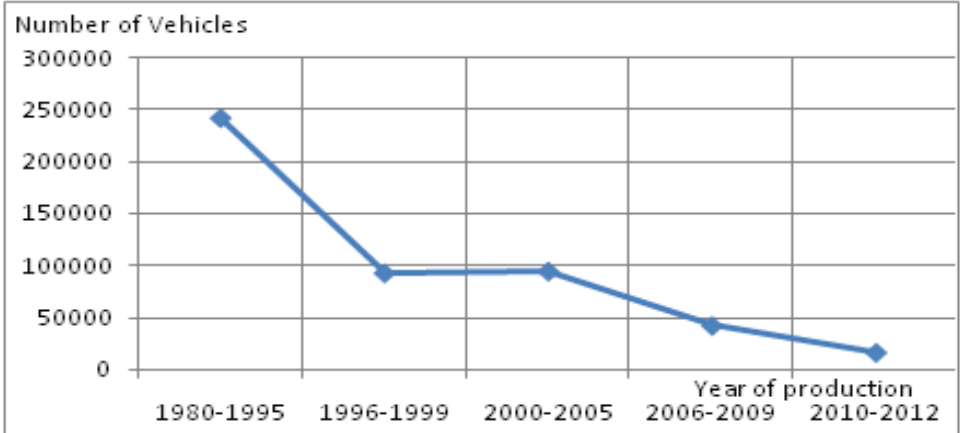

2 Source: The archive's central of General Directorate of Road Transport Services www.dpshtrr.org.al

3 Source: The archive's central of General Directorate of Road Transport Services www.dpshtrr.org.al 


\section{Determination of the pollution quantity in the junction}

\section{a) For the current vehicles structure in circulation}

The calculation of pollution quantity caused by vehicles will be done assuming that the vehicles are with regular technical state and the pollution level is within the limits of the EU norms, given in $\mathrm{g} / \mathrm{km}$ (Table 1,2). These limits of pollution are calculated for the slow movement during junction, according to the average respective speed, for each pollutant element in $\mathrm{g} / \mathrm{min}$.

For the average speed $0.05 \mathrm{~km} / \mathrm{min}$, calculated values of pollutants $\mathrm{CO}, \mathrm{NOx}$ $+\mathrm{HC}$, and PM, by production year are shown in figure 5, for diesel vehicles and in figure 6 , for gasoline vehicles.

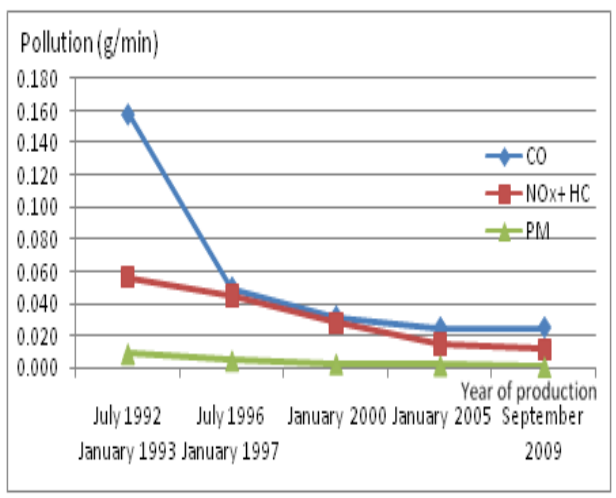

Figure 5. The pollution values CO, NOx + HC, and PM in $\mathrm{g} / \mathrm{min}$, for diesel vehicles

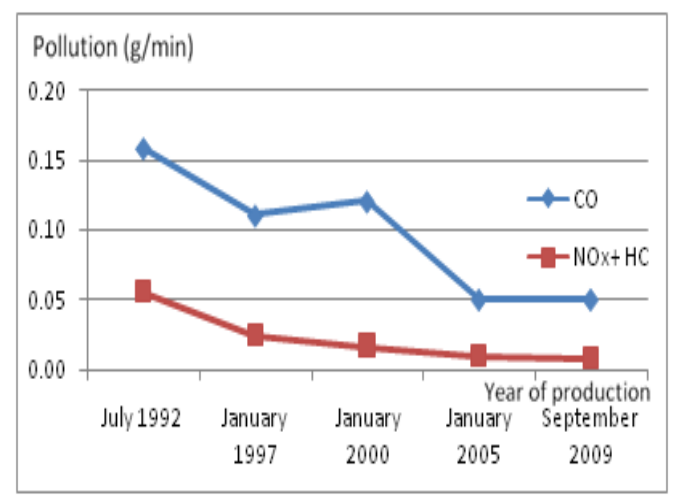

Figure 6. The pollution values $\mathrm{CO}, \mathrm{NOx}+\mathrm{HC}$ in $\mathrm{g} / \mathrm{min}$, for gasoline vehicles

The pollution quantity issued from vehicles in $\mathrm{g} / \mathrm{h}$ at the "Zogu Zi" junction, for each pollutant, $\mathrm{CO},(\mathrm{HC}+\mathrm{NOx})$ and $\mathrm{PM}$, can be calculated:

For diesel vehicles:

$G_{d}=\left(G_{1} P_{1}+G_{2} P_{2}+G_{3} P_{3}+G_{4} P_{4}+G_{5} P_{5}\right) 600,79 N h[g / h]$

For gasoline vehicles:

$G_{g}=\left(G_{1} P_{1}+G_{2} P_{2}+G_{3} P_{3}+G_{4} P_{4}+G_{5} P_{5}\right) 600,21 \mathrm{Nh}[\mathrm{g} / \mathrm{h}]$

The total pollution quantity in this junction, for each element will be:

$$
\mathrm{G}=\mathrm{G}_{\mathrm{d}}+\mathrm{G}_{\mathrm{g}}[\mathrm{g} / \mathrm{h}]
$$


Where:

- $\mathrm{P}_{1}, \mathrm{P}_{2}, \mathrm{P}_{3}, \mathrm{P}_{4} \mathrm{P}_{5}$ - are the percentages of vehicles in circulation, by groups of production years, respectively before 95, 1996-1999, 2000-2005, 2006-2009 and after 2010 for the current situation obtained from figure 4, from which we have: $\mathrm{P} 1=54 \%, \mathrm{P} 2=20 \%, \mathrm{P} 3=18 \%, \mathrm{P} 4=6 \%, \mathrm{P} 5=2 \%$.

- $G_{1}, G_{2}, G_{3}, G_{4}, G_{5^{-}}$are pollution mass in $\mathrm{g} / \mathrm{min}$ for each pollutant, by five groups of production years, respectively before 95, 1996-1999, 2000-2005, 20062009 and after 2010, given in figure 5, for diesel vehicles and in figure 6 for gasoline vehicles.

\section{b) For the proposed vehicles structure in circulation}

In this case, we assume that the vehicle number at the junction is the same as the current structure, while the vehicles structure will be by the importing of vehicles in year $2011^{4}$ (Figure 7), in which diesel vehicles make up $55 \%$ of vehicles manufactured after 2000. This is most likely, due to higher taxation of used vehicles in Albania.

Figure 7. Vebicle number registered in 2011, according to the production year

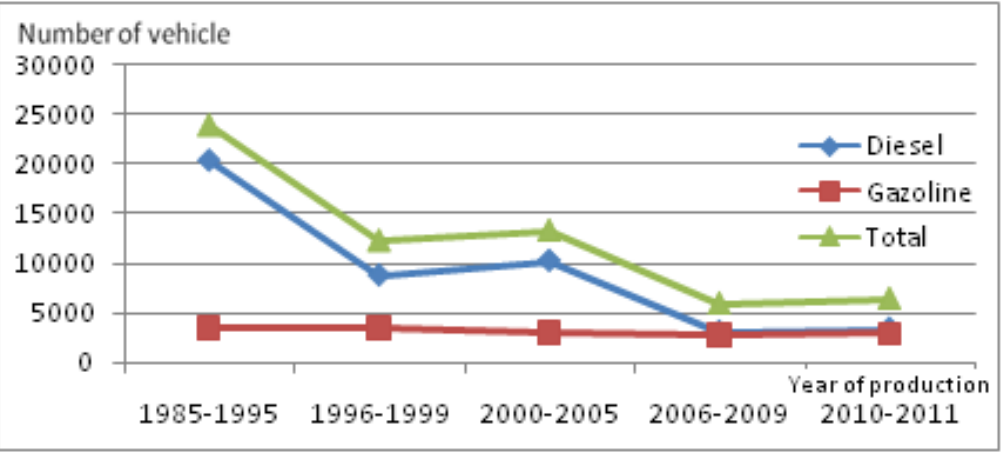

Thus, the pollution quantity issued from vehicles in $\mathrm{g} / \mathrm{h}$ at the " Zogu Zi" junction, for each element $\mathrm{CO}, \mathrm{HC}+\mathrm{NOx}$ and $\mathrm{PM}$, for the proposed structure can be calculated:

For diesel vehicles:

$$
\mathrm{G}_{\mathrm{d}}^{\prime}=\left(\mathrm{G}_{3} \mathrm{P}_{3}^{\prime}+\mathrm{G}_{4} \mathrm{P}_{4}{ }_{4}+\mathrm{G}_{5} \mathrm{P}_{5}^{\prime}\right) 600.55 \mathrm{Nh} \quad[\mathrm{g} / \mathrm{h}]
$$

For gasoline vehicles:

$$
\mathrm{G}_{\mathrm{g}}^{\prime}=\left(\mathrm{G}_{3} \mathrm{P}_{3}+\mathrm{G}_{4} \mathrm{P}_{4}+\mathrm{G}_{5} \mathrm{P}_{5}^{\prime}\right) 600.45 \mathrm{Nh} \quad[\mathrm{g} / \mathrm{h}]
$$

${ }^{4}$ Source: The archive's central of General Directorate of Road Transport Services www.dpshtrr.org.al 
The total pollution quantity in this junction, for each element will be:

$$
\mathrm{G}^{\prime}=\mathrm{G}_{\mathrm{d}}^{\prime}+\mathrm{G}_{\mathrm{g}}^{\prime}[\mathrm{g} / \mathrm{h}]
$$

Where

- $\mathrm{P}_{3}, \mathrm{P}_{4}, \mathrm{P}_{5}$ - represent the vehicles percentages in circulation for the proposed structure with vehicles manufactured in 2000-2005, 2006-2009 and after 2010. In this case, according to records made in 2011 (Figure 7), we have: $\mathrm{P}_{33}=52 \%, \mathrm{P}_{4}^{\prime}$ $=23 \%, \mathrm{P}_{5}=25 \%$.

On the basis of formulas 2-7, pollution quantities per hour for the main pollutants $\mathrm{CO}, \mathrm{NOx}+\mathrm{HC}$ and $\mathrm{PM}$, are calculated for the current structure of vehicles in circulation and for the proposed structure, which are shown in table 3 and in the form of graphs in Fig. 8.

The pollution quantity caused by vehicles at the " $\mathrm{Zogu} \mathrm{Zi"}$ junction is too high and reached to $486 \mathrm{~kg} \mathrm{CO}, 204 \mathrm{~kg}(\mathrm{NOx}+\mathrm{CH})$ and $22.5 \mathrm{~kg}$ particles PM per day.

\section{Table 3}

\begin{tabular}{|c|c|c|c|}
\hline Vehicle variants in circulation & $\begin{array}{c}\mathrm{CO} \\
(\mathrm{Kg} / \mathrm{h})\end{array}$ & $\begin{array}{c}(\mathrm{NOx}+\mathrm{HC}) \\
(\mathrm{Kg} / \mathrm{h})\end{array}$ & $\begin{array}{c}\mathrm{PM} \\
(\mathrm{Kg} / \mathrm{h})\end{array}$ \\
\hline Current vehicle structure in circulation & 37.6 & 15.8 & 1.75 \\
\hline $\begin{array}{c}\text { The proposed structure with vehicles } \\
\text { manufactured after 2000 }\end{array}$ & 17.6 & 4.1 & 0.5 \\
\hline
\end{tabular}

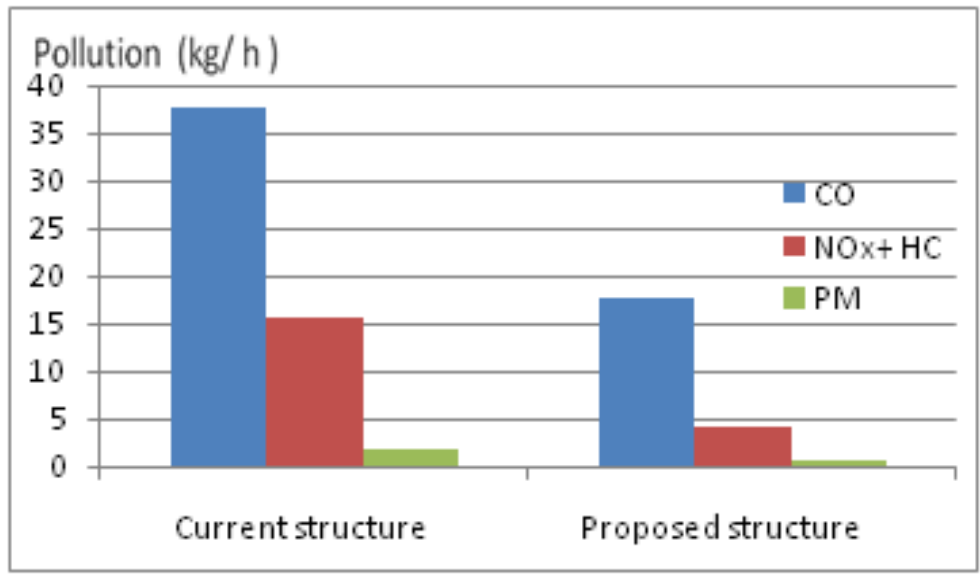

Figure 8 The pollution quantity during the day to the current and proposed structure

Results show that pollution quantity caused by vehicles at the given junction is too high and this is affected from the vehicles structure in circulation, where in 
our country prevail produced vehicles before 1996 more than 2 times compared to those manufactured after 2000.

The traffic flow has a major impact for pollution of this junction. From the results, it seems that the optimal time of crossing the junction is $0.9 \mathrm{~min}$, corresponding to 90 vehicles/min, where the distance described by vehicle goes up to $80 \mathrm{~m}$ and speed up to $0.1 \mathrm{~km} / \mathrm{min}$. If the traffic flow will increase over 90 vehicles / min the crossing time of the junction increases over 2 times and speed decreases to $0.06 \mathrm{~km} / \mathrm{min}$. So, to ensure a sustainable transport and to reduce environmental pollution at this junction, must not circulate more than 100 vehicles/min. Due to the increase of the traffic flow on the Durres road, Arrangement Commission of Territory should schedule other route for the introduction of vehicles in Tirana.

Analysis of the results obtained from table 3 , shows that if in given junction we will use the proposed structure only with vehicles manufactured after 2000 in the circulation, may be achieved a pollution reduction of carbon monoxide $\mathrm{CO}$ 2.1 times, $(\mathrm{NOx}+\mathrm{HC}) 3.8$ times, and particle PM 3.5 times, with an average reduction of pollution at the junction over 3 times. To make possible the realization of the proposed structure, it should be limited the importation of used vehicles and the circulation of existing vehicles, manufactured before 2000 . This can be achieved by reducing or removing the customs tax for vehicles manufactured after 2001 and by introducing environmental pollution tax, proportional to the degree of pollution of the vehicle in use for existing vehicles, that exceed pollution degree. This fee will help to reduce pollution due to exacerbation of technical status, because the user will maintain the vehicles in use. Also control of pollution should be obliged during the technical inspection

\section{Conclusions and Recommendations}

1. High environmental pollution from vehicles at the "Zogu Zi" junction is caused by produced vehicles before 1996, which in Albania dominate in the circulation over 2 time and have a pollution degree over 3 times higher than those produced after 2000 .

2. The traffic flow over 90 vehicles/min at this junction, leads to the increase of the crossing time of junction over 2 times and consequently to the pollution increase. This necessitates the need for a other road for the introduction of vehicles in Tirana from the north direction

3. The proposed structure with produced vehicles after 2000 in junction, lead to the environmental pollution reduction in this urban junction up to 3 times. The circulation limitation of produced vehicles before 2000 could be achieved, if customs duty is reduced for vehicles manufactured after 2000 and the 
environmental tax is decided proportional to pollution degree of vehicle in circulation, that exceed pollution degree.

\section{References}

Air Pollution ( march 2012); Retrieved from http://www.nutramed.com/environment/airpollution.htm

Car Exhaust, Air Pollution, Combustion Engines, (February 2010); Retrieved from http://www.nutra.med.com/environment/carsepa.htm

Gjevori Sh. (2011) “Traffic Engineering” Book 1 Tirana (In Albanian).

Hajderi A. (2010) "On the reduction of environmental pollution caused by automobile emissions"; Journal of studies on economics \& society" Vol.2 2/2010 p. 115-124.

Hajderi A., Gjevori.Sh.(2012) "Case Study for the Reduction of Pollution from Vehicles in Urban Areas in Albania" International Journal of Mechanical \& Mechatronics Engineering IJENS, Vol: 12 No: 06 December p.23-27.

Hillier V.A.W. \& Peter Coombes (2005) "Hillier's Fundamentals of Motor Vehicle Technology" $5^{\text {th }}$ edition Book 1. p. 233.

Instruction No. 12, dated 15.06.2010 of MPWT, "On some changes in instruction no. 6527, dated 24.12.2004 "On the permissible values of the elements of air pollutants in the environment from emissions and noise caused by road vehicles and methods of their control" (In Albanian), art. 11.

"Regulation (EC) No 715/2007 of the European Parliament and of the Council of 20 June 2007 on type approval of motor vehicles with respect to emissions from light passenger and commercial vehicles (Euro 5 and Euro 6) and on access to vehicle repair and maintenance information". Eur-lex.europa.eu. http://eurlex.europa.eu/LexUriServ/LexUriServ.do?uri=CELEX:32007R0715:EN: $\underline{\mathrm{NOT}}$ 